\title{
ARTIGOS
}

\section{Sociedade civil e Gramsci: desafios teóricos e práticos}

\section{Civil society and Gramsci: theoretical and practical challenges}

\section{Luiz Eduardo W. Wanderley*}

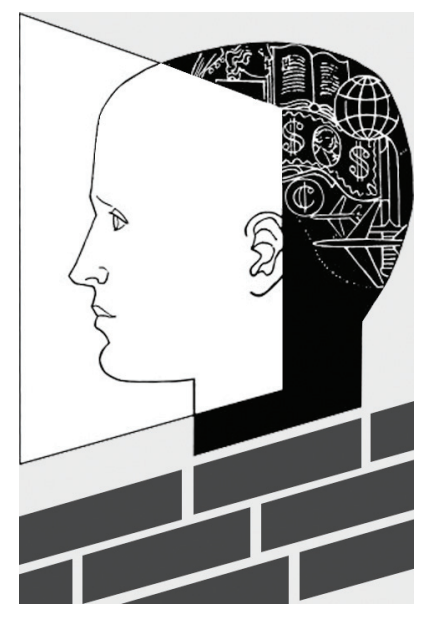

Resumo: O texto busca analisar algumas interpretações teóricas e práticas da realidade brasileira, em especial, a partir de algumas concepções de Gramsci: significado de Sociedade Civil, inter-relações entre infraestrutura e superestrutura, papel dos intelectuais orgânicos, participação das classes e setores sociais organizados, controle das políticas públicas e dimensão cultural, utilizando conceitos extraídos de publicações gramscianas e de um conjunto de intérpretes, com a devida cautela da aplicação de seu legado e interlocução com outras correntes de pensamento.

Palavras-chave: Sociedade civil. Bloco histórico. Intelectuais orgânicos. Democracia. Crise do capitalismo.

\begin{abstract}
The text analyzes the theoretical and practical interpretations of the Brazilian reality, particularly based on some of Gramsci's concepts: meaning of civil society, interrelationship between infrastructure and superstructure, organic intellectuals' role, participation of both the social classes and sectors of the organized society, control of public policies, and cultural dimension. Such analysis is done using concepts extracted from Gramsci's publications and from a group of interpreters. The application of his legacy and the dialogue with other lines of thought were taken into consideration.

Keywords: Civil society. Historic segment. Organic intellectuals. Democracy. Capitalism crisis.

* Professor titular do Departamento de Sociologia da PUC-SP — São Paulo/SP, Brasil; sociólogo, ex-reitor da PUC-SP (1984-88), coordenador do Núcleo de Estudos Latino-Americanos (Nelam), sócio da Ação Educativa e membro do Conselho do Cesep.E-mail: csopos@pucsp.br.
\end{abstract}




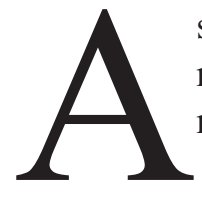

s reflexões e significados sobre sociedade civil (utilizarei esta noção, no conjunto do texto, para facilitar, como SC) apontam a sua heterogeneidade e complexidade, os consensos e dissensos conhecidos.

Em textos por mim elaborados, com finalidades diversificadas, procurei ordenar evidências, distinguir argumentos plausíveis, explicitar minha visão sobre a constituição, o funcionamento e a direção de setores sociais relevantes que fazem parte da sociedade civil brasileira, utilizando basicamente uma compreensão ancorada nas elaborações de Gramsci, sem concordar com todas as suas interpretações analíticas e práticas delas derivadas. Um exemplo pode ser encontrado em artigo publicado (Wanderley, 1999), no qual estabeleço os embriões de meu entendimento nas relações difíceis e conflitivas entre a $\mathrm{SC}$, o Estado e o mercado. No presente texto, busco expor o seu entendimento com base em algumas das interpretações atuais e eixos analíticos elaboradas pelas reflexões gramscianas, considerando que elas foram formuladas a partir de "análises concretas de situações concretas" de sua trajetória histórica; efetuando ressignificações e inflexões e, além disso, ciente de que seus intérpretes e analistas ora convergem ora divergem em pontos essenciais. A intenção está em recuperar elementos que considero essenciais para a temática proposta neste número especial da revista, objetivando colocar um pano de fundo que colabore de forma teórica e prática. Para alcançar este objetivo, a exposição utilizará citações de Gramsci, extraídas de seus escritos, além de alguns outros autores que fazem referências diretas a essas citações e suas interpretações [as citações são longas para assegurar como emanam diretamente dos autores e evitar repetições pessoais sobre as mesmas]. Reconhecemos que seu legado teórico não contém respostas prontas e completas para todos os desafios teóricos e práticos que sua obra coloca para o entendimento do capitalismo, e sim caminhos que permitem repensar as contradições e os reptos postos pelas formações socioeconômicas e pelos modos de produção capitalistas em sua complexidade atual. Nas palavras de Simionatto (1995, p. 254-255),

precisamos ler Gramsci não apenas situando-o em seu tempo, mas situando-o hoje, na história que estamos vivendo e que ele não viveu: retomar seu discurso criador, não no vazio nebuloso de desejos e sonhos, mas a partir da concretude real e histórica. O seu legado não nos ajuda apenas a pensar o passado, mas põe no presente a perspectiva da revolução, que é hoje a luta pela democracia e pelo socialismo.

É preciso retificar o que ficou anacrônico e abrir a interlocução com outras correntes de pensamento. 
Desde logo, é necessário discernir com cuidado as colocações de Gramsci e sua aplicação teórica e prática na realidade brasileira. Marco Aurélio Nogueira chama a atenção para estas diversas interpretações, que convém registrar:

Gramsci foi rapidamente difundido no Brasil, mas acabou por funcionar como "meio" para o estabelecimento de um descompromissado flerte com o marxismo e para emprestar autoridade às ideias mais estranhas, regra geral arquitetadas a partir de uma operação preocupada em manipular as categorias gramscianas como se tratasse da peça de um puzzle cuja resolução pouco interessava. Seu pensamento terminou assim por ser reduzido a conceitos, desvinculado de qualquer dimensão doutrinária mais abrangente e, sobretudo, separado da perspectiva de transformação socialista e da particular teoria do Estado que fazem de Gramsci um ponto de inflexão na história do marxismo e do movimento operário. (Nogueira, 1988, p. 131)

Este autor quer enfatizar a necessidade de superar a fragmentação inerente à obra de Gramsci e buscar a unidade e a visão de mundo subjacente a ela.

\section{Interpretações sobre o conceito}

Uma citação estimulante sobre o entendimento da SC a interpreta como "o conjunto dos organismos vulgarmente chamados privados [...] e que correspondem à função de hegemonia que o grupo dominante exerce em toda a sociedade" (Gramsci, 1972, p. 16). Gramsci afirma que sua reflexão o havia levado

a certas características do conceito de Estado, o qual geralmente é entendido como sociedade política (ou ditadura ou aparato de coerção) [...] e não como equilíbrio entre a sociedade política e a sociedade civil (ou hegemonia de um grupo social sobre toda a sociedade nacional), exercida por meio de organizações que costumamos considerar privadas, como a Igreja, os sindicatos, as escolas etc. (Gramsci, 1973, p. 272)

Na apreciação de Acanda (2006, p. 179):

Família, igrejas, escolas, sindicatos, partidos, meios de comunicação de massa e até mesmo o senso comum compartilhado por todos, e que determina aquilo que é aceito como normal, natural e evidente, são elementos de um espaço cuja denominação como sociedade civil não indica seu alheamento em relação às lutas políticas pelo poder, mas um campo específico do aprofundamento da hegemonia de uma classe. Ainda que as instituições repressivas continuem sendo um instrumento imprescindível para 
a classe dominante, a coerção absoluta nunca foi uma opção viável. No capitalismo, a burguesia se vê obrigada a buscar e a organizar ativamente o consenso — ainda que passivo - dos dominados. E consegue organizá-lo por sua capacidade de disseminar normas políticas, culturais e sociais através das instituições "privadas" da sociedade civil. O Estado é a combinação, em proporções variáveis, de momentos de consenso e momentos de força.

Um resumo das características gerais da SC pode considerar três dimensões complementares (Portelli, 1974, p. 18-19):

- como ideologia da classe dirigente, enquanto abarca todos os ramos da ideologia, desde a arte até as ciências, passando pela economia, o direito etc.;

- como concepção do mundo difundida entre todas as capas sociais, às que liga, deste modo, a classe dirigente, enquanto se adapta a todos os grupos; daí seus diferentes graus qualitativos: filosofia, religião, senso comum, folclore;

- como direção ideológica da sociedade, se articula em três níveis essenciais: a ideologia propriamente dita, a "estrutura" ideológica — quer dizer, as organizações que criam e difundem a ideologia —, e o "material" ideológico, quer dizer, os instrumentos técnicos de difusão da ideologia (sistema escolar, meios de comunicação de massa, bibliotecas etc.).

Evidenciando as oscilações sobre as interpretações mais emblemáticas sobre a SC, assentes nos tempos atuais, com base em distintas interpretações, são catalisadas as seguintes:

Primeiro, as interpretações mais influentes da sociedade civil carregam as tintas da estilização normativa de uma sociedade civil virtuosa e produtora de efeitos democratizadores nos planos político, cultural e econômico. Segundo, a sociedade civil é abissalmente mais heterogênea do que as formulações teóricas do momento da "euforia" levariam a supor, e, por conseguinte - em vez de unificada por compromissos e valores comuns - é perpassada por divergências e conflitos e portadora de características que podem gerar efeitos positivos ou negativos. Terceiro, a sociedade civil ou o conjunto de atores habilitados a se qualificar como parte dela em cada contexto tem assumido funções institucionalmente reconhecidas — por governos nacionais e subnacionais e por instituições multilaterais — no desenho, no controle e na execução de políticas públicas e programas de ajuda, bem como na representação de públicos diversos e interesses difusos. (Ipea, 2010, p. 505) 
Este estudo faz comparações interessantes para os casos mexicano e brasileiro.

No caso brasileiro, a sociedade civil parece mostrar as marcas de uma ativação societal contra a ditadura que apostou na criação e sustentação de atores fora das órbitas do sistema político, cuja capacidade de ação se prolongou em um protagonismo pós-democratização que se dirige a incidir na formação de agenda pública. (Ipea, 2010, p. 533)

Numa perspectiva ancorada em textos dos autores mais significativos que analisaram esta temática, Simionatto traça comentários com base em três concepções. A primeira se expressa na concepção da sociedade civil liberal-democrática (com base principalmente em Cohen e Arato), que substitui categorias e conceitos relacionados entre estrutura e superestrutura

por argumentações subjetivas relacionadas à dinâmica do "mundo da vida", que em boa medida acabaram por esvaziar a compreensão da sociedade civil como arena de luta política para além das conquistas dos direitos de cidadania. Essa perspectiva aproxima-se das formulações liberais em que a sociedade civil é situada como instância autônoma, espaço de articulação de individualidades, atravessada pela neutralidade de classe. (Simionatto, 2010, p. 38)

A segunda concepção, denominada sociedade civil liberal-corporativa ou neoliberal (com tendências derivadas de M. Walzer, C. Taylor, A. Wolfe, J. Keane e E. Gellner, entre outros), com ênfase no tema da participação, é assim situada por Simionatto (2010, p. 44):

A participação é tomada como inovação metodológica, para conferir maior compromisso e legitimidade às ações de um amplo marco de atores sociais, incluindo ONGs, governos locais, nacionais e internacionais, organizações comunitárias, redes sociais informais, setor privado, sindicatos e grupos organizados diversos.

Resumindo sua posição crítica dessa concepção, ela aponta que a

sociedade civil foi reduzida ao âmbito dos interesses privados e corporativos, como uma esfera autônoma, sem conflitos, destituída da prática política em sentido amplo. Nessa concepção, "a luta se faz em termos competitivos e radicalmente privados, sem maiores interferências públicas ou estatais" (Nogueira, 2003, p. 224), onde não há lugar para a disputa da hegemonia, na medida em que a preocupação não é cons- 
truir um novo tipo de Estado, mas contar com o apoio deste meio do acesso aos fundos públicos e da maximização dos interesses privados. Aqui não há espaço para a construção de um projeto sob a hegemonia das classes subalternas [...]. (Simionatto, 2010, p. 46)

A terceira concepção, distinguida por ela, é a gramsciana, na qual o conceito de sociedade civil é instrumento de projeto. Refutando as duas concepções citadas, a autora comenta que na concepção correta há nela:

"um caráter radicalmente classista” (Durighetto, 2006, p. 124), uma dimensão nitidamente política, permitindo retomá-la como esfera da "grande política", o que remete à luta pela hegemonia e à conquista do poder pelas classes subalternas (Coutinho, 2008). Esse movimento implica a criação de alianças estratégicas entre a classe trabalhadora e os movimentos sociais, com vistas a ampliar o horizonte emancipatório, elevando ao máximo de universalidade possível o ponto de vista dos grupos subalternos, cuja síntese é a "vontade coletiva nacional-popular". A sociedade civil definida por Gramsci (Cadernos do Cárcere, 2000, p. 225) significa, assim, “a hegemonia política e cultural de um grupo social sobre toda a sociedade, como conteúdo ético do Estado". (Simionatto, 2010, p. 50)

Exemplificando os abusos conceituais e, por outro lado, a influência internacional do pensamento gramsciano, Acanda (2006, p. 158-160) comenta um dado surpreendente ao comentar a vitória de Blair na Inglaterra, na revista The Economist (25 de outubro de 1997), com o título "Novo trabalhismo, nova linguagem", trazendo uma foto de Gramsci com a legenda: "Gramsci, guru dos gurus". E reproduz parte do texto ali publicado:

É conhecido de todos o fato de o novo trabalhismo ter lançado a política tradicional de esquerda na lata de lixo da histórica britânica [...] Fixemo-nos, porém, na linguagem política e parecerá que agora todos somos marxistas. Muitas das palavras e conceitos preferidos pelos acadêmicos e assessores de Blair são familiares apenas aos leitores de obscuros jornais de esquerda publicados anos atrás. Apresentamos aqui um guia para essas palavras-chave do novo trabalhismo: projeto, cultura, hegemonia. Quando a esquerda viu Margaret Thatcher manter os tories no poder por quase uma geração, recorreram aos trabalhos de Antonio Gramsci, um marxista italiano da década de 1920, para compreender o que havia ocorrido. Gramsci elaborou uma teoria segundo a qual os líderes bem-sucedidos estabeleciam uma "hegemonia" (de forma mais clara, uma dominação) sobre a esfera política mediante o controle do discurso (isto é, dos termos do debate). A esquerda entendeu que Thatcher havia feito o mesmo. Muitos de seus 
integrantes pensam ou esperam que Blair esteja em condições de usar o mesmo artifício. (The Economist, 23 oct. 1997, p. 63)

Gramsci fez suas argumentações tendo em vista os desafios postos pela Revolução Russa e pela crise vigente na Itália de seu tempo. Nas crises recorrentes do capitalismo, por décadas e décadas, e principalmente depois da queda do "socialismo real", retornam questões básicas derivadas de seu pensamento naquela ocasião. Saber se é possível uma mobilização e organização da SC no sentido de romper com as bases deste modo de produção, nas articulações conflitivas entre SC e sociedade política. Para situar uma situação de mudanças profundas, a crise de 2008 e suas repercussões mundiais e nos Estados Unidos releva se já existe condições objetivas para a "crise final do capitalismo". Por um lado, analistas dizem sim, e a maioria diz não.

Wallerstein, enfatizando que todos os sistemas históricos são permeados de contradições, explana sobre o significado de crise.

Usarei o termo "crise" para me referir a uma circunstância rara em que um sistema histórico desenvolve-se até um determinado ponto onde o efeito cumulativo das suas contradições internas impede que que esse sistema possa "resolver" seus dilemas através do "ajustamento" dos seus modelos institucionais em funcionamento. Uma crise é uma situação em que a morte do sistema histórico existente é certa, oferecendo aos que nela se encontram uma escolha histórica: a escolha do tipo do novo sistema histórico a construir ou criar. (Wallerstein, 1984, p. 1)

Comentando épocas e dificuldades para os acumuladores de capital, ele conclui que "estamos vivendo na 'transição', o período de declínio inevitável e a e a 'eventual morte' da economia capitalista mundial" (Idem, p. 8). E, na sequência, traz colocações expressivas sobre a crise da ciência e a dos movimentos sociais.

Hobsbawn (1995) escreve sobre as décadas de crise, o triunfo da "teologia neoliberal" na década de 1980, a perda de poder dos Estados nacionais com o surgimento dos blocos de integração regional. Em tonalidade questionadora, em outro texto, ele defende que:

Se ação pública e de planejamento não for iniciada por pessoas que acreditam nos valores da liberdade, razão e civilização, será iniciada por pessoas que não acreditam nesses valores, porque terá se ser iniciada por alguém. Infelizmente, é mais provável que seja iniciada pelo fenômeno mais perigoso do nosso fin de siècle: regimes nacio- 
nalistas, xenófobos, demagógicos, direitistas, igualmente hostis ao liberalismo e ao socialismo, porque ambos representam os valores da razão, do progresso e a idade das grandes revoluções. Este é o perigo. Rosa Luxemburgo nos advertiu de que a alternativa real da história do século XX era "socialismo ou barbárie". Não temos o socialismo: acautelemo-nos contra a ascensão da barbárie, especialmente barbárie combinada com alta tecnologia (Hobsbawm, 1995, apud Sader).

Economistas de renome estão apontando os erros cometidos por este modo de produção nos últimos anos e, mesmo nos eventos internacionais do G8, G20, Davos etc., os erros são comentados, mas as medidas corretivas - regulamentação do capital financeiro, desenvolvimento sustentável, escapar do calote das dívidas internas de um país etc. — não são concretizadas. Um dado sobre esse tipo de crise foi dado por George Magnus, conselheiro sênior do IBS, um banco suíço que é ícone do capitalismo:

O modelo econômico que conduziu o boom dos anos 1980 a 2008 quebrou. A crise financeira de 2008/9 legou uma crise do capitalismo única em uma geração, cujas pegadas podem ser encontradas em disseminados desafios à ordem política, e não apenas nas economias desenvolvidas [...] porque nosso modelo econômico e a definição de políticas não podem produzir crescimento sustentável, adequada formação de renda ou criação de emprego (Apud Rossi. The Economist, em Folha de S.Paulo, 13 set. 2011, Mundo A13).

Nesse contexto, as clássicas versões de resistência e de lutas dos trabalhadores forjam interpretações díspares (manifestações de rua na Grécia, Espanha, Itália, Inglaterra, Estados Unidos, no contexto de outras), por não envolverem uma "vanguarda", um "partido centralizado". Sem falar das manifestações no mundo árabe, que envolvem disputas entre tribos, culturas, religiões, o que exige novas interpretações sobre para onde seus atores estão se dirigindo. A instabilidade dos mercados e seus efeitos a curto, médio e longo prazos trazem insegurança, instabilidade, dúvidas, cisões nos governos, partidos, sindicatos, igrejas, ou seja, no seio das SC de cada país e dos blocos regionais. As sugestões de Gramsci servem de balizas, meios, mas têm de ser reinterpretadas e ressignificadas.

Perry Anderson (1977), um autor que proclama uma série de discordâncias sobre as posições de Gramsci, naquilo que ele designa como antinomias nas relações entre Estado e $S C$, afirma que a sociedade civil é um conceito prático-indicativo necessário para designar todas as instituições e mecanismos que estão fora das fronteiras do sistema estatal propriamente concebido. 


\title{
Avaliação histórica e composição
}

Desde logo, um alerta no sentido de que, não raro, pesquisas e avaliações sobre a realidade brasileira, principalmente depois dos anos 1970, centraram seus julgamentos em setores organizados em sua maioria referenciados a agentes críticos e transformadores do capitalismo, nos níveis local, nacional e global. Nesta abordagem, muitas vezes foram olvidados ou secundarizados os setores constituídos pelas elites, empresariado rural e urbano, grupos e movimentos conservadores e neoliberais. Alguns analistas trazem à baila uma interpretação esclarecedora, que pode ser vislumbrada nesta citação:

\begin{abstract}
A sociedade civil brasileira, profundamente marcada pela experiência do regime militar instalado em 1964, experimenta, a partir da década de 70, um significativo ressurgimento. Esse ressurgimento, que tem como eixo a oposição ao Estado autoritário, foi tão significativo que é visto, por alguns analistas, como de fato a fundação efetiva da sociedade civil no Brasil, já que sua existência anterior estaria fortemente caracterizada pela falta de autonomia em relação ao Estado (Avritzer, 1994, apud Dagnino, 2002, p. 9).
\end{abstract}

Com toda a cautela necessária, pois estes dois autores explanam bem a complexidade, contradições e ambiguidades inseridas nesta abordagem. O que é preciso deslindar são estas duas noções ambivalentes e que necessitam esclarecimentos: "ressurgimento" e "fundação efetiva". Por um lado, elas corroboram avaliações reconhecidamente positivas, das forças sociais que resistiram e pressionaram a (re)democratização do país, sem esquecer que Dagnino invoca os entraves constituintes do caráter histórico das relações entre Estado e SC, a necessidade de elucidar a noção de projeto político, apregoando "a conhecida e bem difundida visão da sociedade civil como 'polo de virtude' e do Estado como a 'encarnação do mal"' (Dagnino, 2002, p. 281), para ela embasada numa visão reducionista. No entanto, enfocando os termos assinalados, não se pode olvidar que setores sociais conservadores se organizaram e apoiaram a instalação daquele regime, alguns (membros das elites e organizações empresariais, políticas e religiosas) defenderam, posteriormente, com ardor, a repressão, defesa que permanece incólume com algumas exceções exteriorizadas. Veja-se, por exemplo, as dificuldades que aqueles segmentos sociais da SC, apoiando certos segmentos militares, permanecem vigentes, e de como eles se colocam explicitamente contra a visibilidade dos arquivos, bem como os conflitos ope- 
rados com referência à criação da Comissão da Verdade. O que quero evidenciar é o fato de que, em todos os períodos históricos vivenciados pela sociedade brasileira em geral, mesmo reconhecendo que o Estado teve (e ainda tem) um lugar poderoso e atuante, ele esteve organicamente articulado com forças sociais dominantes, elites de setores sociais que comandavam a dinâmica social de municípios e estados, além dos que faziam parte da administração estatal, compunham alianças com os governantes, integrando as relações fundamentais entre a sociedade política e a SC. E que os setores dominantes, alicerçados na globalização neoliberal hegemônica, permanecem atuantes a partir da redemocratização.

Numa outra linha, irrompeu o chamado terceiro setor, que, no geral, de modo distorcido, consciente ou não, acaba se identificando ou se dizendo sinônimo da sociedade civil (primeiro setor — Estado; segundo setor - mercado; terceiro setor — sociedade civil).

Uma primeira constatação deriva exatamente da concepção de sociedade civil, que é composta por um conjunto heterogêneo de atores sociais (incluindo necessariamente setores sociais conservadores e transformadores), que atuam em distintos espaços públicos e com meios específicos de articulação com as estruturas econômicas e políticas. A SC comporta escolas, igrejas, associações, sindicatos, mídia, ONGs, fundações etc. Portanto, o chamado "terceiro setor" é apenas um componente das entidades privadas que a constituem.

Na mesma linha, Dagnino situa, com propriedade, esse entendimento falso, ao afirmar:

Não obstante, por trás da aparente unidade de conceitos e propósitos ocultam-se uma diversidade de projetos e uma ideia pobre e reducionista da sociedade civil, que é cada vez mais reduzida a um amorfo "terceiro setor" em que cabem todos os tipos de associações civis, entendidas como entidades privadas para a ação pública (limitadas a "serviços para terceiros"); desse modo, perdeu-se o perfil crítico que a ideia de sociedade civil continha em meados dos anos de 1990). (Dagnino, Olvera e Panfichi, 2006, p. 22)

\section{Estado ampliado}

Uma das dimensões analíticas de fundo na visão gramsciana está na necessária integração dialética, na concepção de Estado. O Estado, em estrito 
senso, é concebido como sociedade política, e, em lato sensu, como sociedade política mais sociedade civil, vinculando coerção e consenso. A argumentação básica desta abordagem está na concepção dele sobre a superestrutura. Nela, pois, encontram-se:

A sociedade política está constituída pelos órgãos das superestruturas encarregados de implementar a função de coerção e domínio, ao passo que a sociedade civil é conformada pelo conjunto de organismos, usualmente considerados "privados", que possibilitam a direção intelectual e moral da sociedade, mediante a formação do consenso e a adesão das massas. A trama da sociedade civil é formada por múltiplas organizações sociais, de caráter cultural, educativo e religioso, mas também político e, inclusive, econômico. Por seu intermédio, difundem-se a ideologia, os interesses e os valores da classe que domina o Estado, e se articulam o consenso e a direção intelectual e moral e intelectual do conjunto social. Nela se forma a vontade coletiva, se articula a estrutura material da cultura e se organiza o consentimento e a adesão das classes dominadas. (Acanda, 2006, p. 175)

No cerne da definição de Gramsci: "Estado = sociedade política + sociedade civil, quer dizer, hegemonia revestida de coerção" (Gramsci, 1972, p. 165). Ou "Estado, em seu significado integral, ditadura + hegemonia" (Gramsci, 1964, p. 172).

Nesta perspectiva, existem, de forma recorrente, defensores da separação entre SC e sociedade política, e, em contraposição, aqueles que afirmam sua imperativa correlação.

$\mathrm{Na}$ análise sobre a reforma da reforma do Estado, Nogueira mostra como o reformismo prevaleceu na década de 1990 e entronizou uma visão de SC inserida nessa reforma. E enfatizou que para que haja reformas substantivas que conduzam a um Estado ativo, competente e democrático, a SC precisa ser igualmente forte, ativa e democrática. Mas trouxe uma crítica significativa:

O discurso reformista privilegiou unilateralmente a importância da sociedade civil no contexto e na dinâmica da reforma do Estado. Tratou de valorizar precisamente sua contribuição para a gestão e a implementação de políticas. Assim concebida, a sociedade civil conteria um incontornável vetor antiestatal: seria um espaço diferente do Estado, não necessariamente hostil a ele mas seguramente "estranho" a ele, um ambiente imune a regulações ou a parâmetros institucionais públicos - um lugar, em suma, dependente bem mais de iniciativa, empreendedorismo, disposição cívica e "ética" do que de perspectiva política, organização política e vínculos estatais. O discurso alternativo, por sua vez, ainda que impulsionado pelas ressonâncias de sua 
fase anterior, espelhará a operação semântica oficial. Abandonará a fronteira do Estado como campo de lutas de emancipação para se concentrar numa ideia de Estado como espaço de regulação, elaboração e implementação de políticas. Haverá menos antagonismo e mais consenso racional, menos democracia política e mais deliberação democrática. (Nogueira, 2004, p. 59)

Resumindo, a SC seria "um locus em que não nasceria nenhum movimento de crítica política, contestação da ordem ou oposição ao poder (Nogueira, 2004, p. 60).

Comentando o Plano Diretor de Reforma do Aparelho do Estado (1995), fazíamos uma crítica à sua focalização no chamado "público não estatal”, como foi interpretado:

“[...] no Plano há uma concepção do Estado no sentido de aumentar a sua governança nos marcos próprios da democracia representativa, com um enfoque que limita a participação da sociedade civil, entendida no texto quer pelo ângulo dos serviços que são atinentes ao mercado, quer pelo ângulo dos serviços não exclusivos em que se propõem formas de parceria. No documento oposicionista [Um Brasil para os brasileiros - teses para a elaboração do Programa Democrático e Popular Brasil-1998, elaborado por uma Comissão de representantes dos partidos - PT, PSB, PDT e PCdoB], há uma valorização de uma democracia social ampliada, com acento na extensão da cidadania e na mobilização da sociedade civil para que exerça um controle social sobre o Estado. (Raichelis e Wanderley, 1998)

\section{Participação e controle social: a atuação dos trabalhadores}

Tendo por referência a posição de Gramsci, no contexto italiano da sua época, é válida sua ideia de dilatar a comissão interna (constituída em 1905 na empresa Ítala) e reunir um conselho operário, representativo dos operários sindicalizados e em geral, dos empregados e dos técnicos. Para isto, foi criada a revista Ordine Nuovo, que deveria se tornar um órgão dos conselhos de fábrica, para conscientizar o operariado de sua função política e histórica. Mesmo supervalorizando a necessidade do partido, Gramsci mostra a riqueza das instituições e atividades existentes.

As comissões internas são órgãos da democracia operária, que devem ser libertados das limitações impostas pelos empresários e aos quais deve infundir vida nova e 
energia. Hoje, as comissões internas limitam o poder do capitalismo na fábrica e desempenham funções de arbitragem e de disciplina. Desenvolvidas e enriquecidas, deverão ser amanhã os órgãos do poder proletário, que substitui o capitalista em todas as suas funções úteis de direção e de administração. Já a partir de agora os operários deveriam proceder à eleição de vastas assembleias de delegados, escolhidos entre os camaradas melhores e mais conscientes, sobre a base da palavra de ordem "todo o poder das fábricas aos comitês de fábrica", coordenada a uma outra: "todo o poder do Estado aos conselhos operários e camponeses”. (Gramsci, 1954, p. 147)

$\mathrm{Na}$ história brasileira, ficou patenteada a complexidade dos conselhos de fábrica e dos conselhos populares. Uma alternativa veio com as experiências da economia solidária, motivo de polêmicas. Sempre com os limites de cada situação concreta, certos aportes gramscianos podem ser encontrados nela:

A solidariedade na economia só pode se realizar se ela for organizada igualitariamente pelos que se associam para produzir, comerciar, consumir ou poupar. A chave desta proposta é a associação entre iguais em vez do contrato entre desiguais. $\mathrm{Na}$ cooperativa de produção, protótipo de empresa solidária, todos os sócios têm a mesma parcela do capital e, por decorrência, o mesmo direito de voto em todas as decisões. Este é o seu princípio básico. Se a cooperativa precisa de diretores, estes são eleitos por todos os sócios e são responsáveis perante eles. Ninguém manda em ninguém. E não há competição entre os sócios: se a cooperativa progredir, acumular capital, todos ganham por igual. Se ela for mal, acumular dívidas, todos participam por igual nos prejuízos e nos esforços para saldar os débitos assumidos. (Singer, 2002, p. 9-10)

Para Paulo Singer a economia solidária é outro modo de produção, cujos princípios básicos são a propriedade coletiva ou associada do capital e o direito à liberdade individual. Ele sustenta a necessidade de uma renda cidadã; da autogestão - contrária à heterogestão; das lutas emancipatórias que modifiquem as instituições para a concretização de práticas democráticas; da constituição de redes de cooperativas.

Um meio relevante de atuação, constante da Carta Magna (1988), diz respeito aos conselhos gestores. Tatagiba (2000) destaca que os conselhos gestores de políticas públicas constituem espaços públicos de composição plural e paritária entre Estado e SC. E assinala sua significação relevante como: espaços públicos com composição plural e paritária; buscarem a resolução dos conflitos derivados dos distintos interesses em jogo no processo dialógico; funcionarem como instâncias deliberativas conduzindo para a democratização da gestão. Mesmo reconhecendo as dificuldades de uma avaliação mais profunda, para ela 
os conselhos representam importante avanço na construção de formas mais democráticas de gestão nas atividades públicas, com destaque para certos pontos resultantes da pesquisa efetuada: a) "o princípio da paridade tende, pelas próprias características de nossa cultura política, a se traduzir em vantagens para o governo..." (2000, p. 59); b) os vínculos entre os representantes governamentais e seus órgãos de origem são frágeis, pois "os conselheiros governamentais tendem a defender nos conselhos suas próprias opiniões, e não as propostas e posicionamentos resultantes da discussão com as agências estatais envolvidas" (2000, p. 63); c) "os conselheiros não governamentais têm encontrado pouco respaldo e acompanhamento de suas ações por parte da entidades que representam" (2000, p. 65); d) o reconhecimento unânime da falta de capacitação dos conselheiros; d) recusa das instâncias governamentais em partilhar o poder, o que leva à fragilidade deliberativa. Com base em outra abordagem analítica e fruto de pesquisa, se, em alguns casos, houve avanços reconhecidos nestes campos, não de pode esquecer que

sua multiplicação e pulverização estão a exigir um debate mais profundo em termos da fragmentação das demandas sociais e da definição de estratégias que possam articular propostas e ações dos vários conselhos, em termos de reconstruir a perspectiva de totalidade da política social [...] o estímulo genérico às ações de parceria e às iniciativas autônomas tende a reforçar práticas de desresponsabilização do Estado em nome do fortalecimento da sociedade civil. (Raichelis e Wanderley, 1999, p. 124-125)

Outras avaliações procuram demonstrar as enormes dificuldades de uma efetiva participação social no caso brasileiro, na conquista de uma ampliação e constituição de uma esfera pública, diferenciada da estatal. O Estado é capaz de responder às demandas apresentadas pelos conselheiros? A participação social, entendida como controle social "pode estar levando paradoxalmente a uma despolitização das políticas públicas, dada a natureza dos colegiados e a sua forma de funcionamento - atuação de forma ritualística, composição viciada por nepotismo ou compadrios" (Cohn, 2010, p. 495).

Uma instância de participação tem sido o Conselho de Desenvolvimento Econômico e Social (CDES), que tenta aglutinar várias forças sociais no debate sobre macroproblemas, que são foco de políticas nacionais. Apesar de nele estarem participantes dos trabalhadores assalariados, os efeitos concretos das reuniões não afetam diretamente as políticas públicas, mesmo porque o CDES não tem poder deliberativo. 
Essas reuniões acabam funcionando muito mais como busca de legitimação das macropolíticas governamentais, em que o consenso não é fundamental, já que o que está em jogo não é a definição de políticas e programas, nem sua tradução na implementação de medidas específicas. (Cohn, 2010, p. 493)

Outra instância de participaçãose constitui no Orçamento Participativo — OP, sempre tendo em vista, do mesmo modo, críticas profundas. Porém alguns analistas o encaram como motor de participação:

[...] por tratar de questões que afetam de forma mais direta a população - e notadamente os setores mais carentes e dependentes dos serviços estatais - OP apresenta um importante potencial de motivação à participação. Além disso, a participação e a adesão ao processo do orçamento participativo revelam uma coincidência de interesses sociais e políticos através dos objetivos e resultados do OP. Que vem se mostrando como alternativa confiável de resolução de demandas sociais. Trata-se, portanto, de uma política de soma positiva: o Estado mantém e aumenta sua legitimidade e capacidade de implementação de políticas, bem como a população vê atendidas as reivindicações que foram por ela demandadas. (Lüchmann, 2006, p. 126)

Quando se avalia a presença de setores organizados da SC, nos dias atuais, temos uns poucos (movimentos sociais, ONGs, pastorais) que criticam, pressionam, contestam o modelo vigente e se opõem ao poder estatal. E uma maioria, nas elites, no empresariado e mesmo nos trabalhadores (centrais sindicais), cuja participação na administração pública, nas articulações com os partidos políticos, no diálogo com os governantes, abandona essa estratégia transformadora.

É no plano internacional, tendo em vista os impactos da globalização neoliberal, a reestruturação produtiva e privatização das políticas sociais e seus efeitos negativos sobre os trabalhadores, que redes, associações, fóruns internacionais constituídos por eles conseguem construir resistências e negociações de maior ou menor monta. No plano mundial, o Fórum Social Mundial, com seu lema "um outro mundo é possível”, e agora descentralizado em fóruns, regionais, continentais e nacionais, constitui uma ferramenta instigante na busca de alternativas transformadoras. Para exemplificar com um caso brasileiro, uma pesquisa de mestrado investigará como os trabalhadores da Mercedes-Benz do Brasil reagiram nesse contexto, no período de 1992 a 2002 (projeto de dissertação de Eduardo Magalhães Rodrigues, do Programa de pós em Relações Internacionais San Tiago Dantas, apresentado em 2011). Ele questiona se a negociação diplomática, ao reverso da utilização da força, na perspectiva da 
interdependência complexa (baseado em Robert Keohane e Joseph Nye), é uma solução condizente com uma mutação profunda. E cita a criação do Comitê Mundial de Trabalhadores da Daimler-Chrysler - CMTDC, em 2002, como uma conquista, que constituiu o Acordo Marco Internacional - AMI em 2002. Nas palavras do mestrando, os "Amis são um dos mais novos instrumentos da política sindical internacional através dos quais os sindicatos globais (GUFs - Global Union Federations) ou outras entidades sindicais internacionais como os CMTDCs assinam junto às EMNs um conjunto de medidas que visam garantir conquistas sociais e econômicas de todas as unidades de uma mesma. No caso do então grupo Daimier-Chrysler, o AMI assinado em 2002 beneficia 372 mil trabalhadores em 21 países e aborda, entre outros temas, questões relacionadas aos direitos humanos, trabalho forçado, trabalho infantil, relações sindicais, condições de trabalho, saúde e segurança ocupacional, jornada de trabalho, qualificação etc. As medidas são para serem cumpridas não só pelas unidades propriamente ditas da DC, mas também por sua cadeia de fornecedores. O AMI trata igualmente dos procedimentos de implantação."Na trajetória dos brasileiros foram relevantes relações de intercâmbio com sindicatos e comissões de fábrica de outros países (principalmente Alemanha), a criação do projeto "Fábrica 2000" da Mercedes-Benz brasileira, que conduziu o SMABC a elaborar uma proposta alternativa à reestruturação produtiva da empresa, na chamada "Qualidade de Vida no Trabalho". Um questionamento de fundo está em se saber se essas práticas concretas, e sua elaboração teórica, condizem com as propostas contidas nas estratégias formuladas por Gramsci.

\section{Intelectuais orgânicos}

Outra questão fundamental se cinge a quem exerce a vinculação entre a infraestrutura e a superestrutura. São os chamados intelectuais orgânicos, esclarecendo que este caráter orgânico se define em cada bloco histórico. Eles se constituem a partir das classes fundamentais no campo econômico; e o vínculo orgânico advém quando o intelectual, os mais importantes e complexos provêm da classe que representa.

Cada grupo social, ao nascer no terreno originário de uma função essencial no mundo da produção econômica, se cria, conjunta e organicamente, um ou mais segmentos de 
intelectuais que lhe dão homogeneidade e consciência da própria função, não somente no campo econômico, mas também no social e no político. (Gramsci, 1972, p. 9)

Isto é válido para as camadas superiores de intelectuais e organizadores políticos (chefes de empresas, grandes proprietários de terras, administradores de grandes fincas, empresários comerciais e industriais etc.). No caso das classes subalternas, no geral, além de uns poucos representantes originários dessas classes, eles "importam" intelectuais, o que torna o contexto ambivalente. "Poder-se-ia medir a 'organicidade' dos diversos estratos intelectuais e sua conexão mais ou menos estreita com um grupo social fundamental, fixando uma graduação das funções e das superestruturas e baixo para cima (desde a base estrutural para cima)" (Gramsci, 1972, p. 16).

Os intelectuais têm papel fundamental no exercício da hegemonia e da dominação. O autor coloca-os num espaço importantíssimo. Com base nos seus argumentos, Portelli traz elementos relevantes sobre sua presença e atuação:

\begin{abstract}
Os intelectuais são as células vivas da sociedade civil e da sociedade política, eles são os que elaboram a ideologia da classe dominante, dando-lhes assim consciência de seu papel e tranformando-a em uma "concepção de mundo" que impregna todo o campo social. No nível da difusão da ideologia, os intelectuais são os encarregados de animar e administrar a "estrutura ideológica" da classe dominante no seio das organizações da sociedade civil (Igreja, sistema escolar, sindicatos, partidos etc.), e seu material de difusão. (Portelli, 1974, p. 98)
\end{abstract}

Como é sabido, o partido operário deve atuar como intelectual coletivo, a quem cabe dirigir os meios de ampliação da consciência da classe trabalhadora.

A classe trabalhadora dispõe de uma gama de outras organizações que lhe são fundamentais na luta contra o capital: sindicatos, associações, comissões de fábrica, frações parlamentares, organizações culturais, ligas de jovens etc. [...] Mas como se pode atingir a direção unitária de organizações tão distintas? [...] Qual é a organização central que se manteve trabalhando em uma linha geral e que, graças a sua autoridade, pode fazer com que todas aquelas organizações se orientem por essa linha, alcançando a coordenação e a unidade e afastando a possibilidade da atuação indevida? Essa organização é o partido do proletariado. (Gramsci, 1980, p. III, apud Costa, 2002, p. 41)

Tanto na União Soviética, quanto em todas as regiões onde atuaram (e atuam) os partidos que dizem representar os interesses do proletariado/opera- 
riado, as oscilações, convergentes e divergentes, sobre a sua natureza e suas práticas, levantam questionamentos robustos sobre essas concepções clássicas e sua aplicabilidade nos tempos atuais.

Fruto de pesquisa acadêmica realizada sobre o Movimento de Educação de Base - MEB (1960-1965), fiz comentários sobre a pedagogia utilizada na educação pelo rádio, meio central na natureza desse movimento. Salientando o lugar e o papel exercido pelos dirigentes e equipes coordenadoras, constituídos por professores, animadores, assessores, provenientes em sua maioria das classes médias, eles traduziam suas atividades no que era conhecido como conscientização e politização (as duas com características convergentes com o "método Paulo Freire", mas com especificidades próprias na conceituação, metodologia e funcionamento em geral). Buscando efetivamente uma educação transformadora que fizesse de seus alunos - maioria de camponeses - sujeitos de sua vida e agentes conscientes e críticos da sociedade na qual viviam, veio à tona o entendimento de quem éramos nós naquele contexto. Como já foi salientado por Simionatto (1995, p. 172), ela destacou trechos que incidem sobre esta temática: "O MEB esforçou-se por captar o saber das classes subalternas, predominantemente o campesinato, e por fim, difundir uma ideologia com certa articulação interna, posto que teoricamente fragmentada". Teriam sido eles intelectuais orgânicos? Qualifiquei os membros do MEB como tendencialmente orgânicos das classes populares, já que "com formas diretas e indiretas, com avanços e recuos, lançaram os embriões de sua hegemonia e participaram, nem sempre conscientemente, da luta político-ideológica pela mudança social do capitalismo na direção que apontava para a nova sociedade (Wanderley, 1984, p. 381).

O questionamento é recorrente na participação dos quadros de ONGs, pastorais e movimentos sociais que mobilizam, educam, organizam setores expressivos das classes populares nos dias de hoje. Ciente das condições mutantes no tempo e espaço, é possível considerar essas pessoas intelectuais orgânicos? Numa tradução direta dos textos de Gramsci não, e acrescido do fato de que muitos deles, inclusive os provenientes do operariado, quando assumem cargos políticos ou públicos, mudam sua visão de mundo, seu comportamento em relação aos trabalhadores, a base popular, não raro caindo em práticas paternalistas, fisiológicas e mesmo autoritárias, desconhecendo os enganos e fragilidades resultantes da atuação dos setores revolucionários em várias partes do globo. No entanto, certos cidadãos e grupos, conscientes dessa história e das 
situações vivenciadas, podem sim ser reconhecidos como intelectuais tendencialmente orgânicos dos trabalhadores e das classes populares.

Cabe uma referência aos "intelectuais tradicionais", vinculados ao antigo bloco histórico, formado pelas camadas de intelectuais que existiam antes da chegada da nova classe fundamental. Na realidade da constituição do capitalismo, a burguesia teve que entrar em conflito com o clero.

A categoria dos eclesiásticos pode ser considerada como a categoria intelectual organicamente ligada à aristocracia rural: juridicamente estava equiparada à aristocracia, com a qual compartia o exercício da propriedade feudal da terra e o uso dos privilégios estatais ligados à propriedade. (Gramsci, 1972, p. 11)

Esta visão é reconhecida por historiadores e abrange até mesmo situações atuais, nas quais eles se colocam ao lado do empresariado e das elites dominantes. Porém, nem sempre é correta, em diversos tempos históricos. Com outro foco, estudiosos comentam a influência da teologia da libertação e como seus adeptos colaboraram (e continuam colaborando) ativamente na mobilização e fortalecimento das massas, das classes subalternas, de movimentos sociais transformadores. Um exemplo está na atuação das CEBs e parte das pastorais sociais. Nos últimos anos, membros do Grito dos Excluídos, do Centro Ecumênico de Evangelização e Educação Popular - Cesep, do Movimento Fé e Política, entre outros, podem ser caracterizados como intelectuais críticos e com participação em ações políticas contestadoras do sistema vigente.

\section{Bloco histórico}

Um ponto nevrálgico na perspectiva analítica que estou adotando traz um conceito mais incisivo e motivo de acirradas controvérsias, qual seja o de bloco histórico, a natureza dialética e orgânica da relação entre estrutura e superestrutura. Nas palavras de Gramsci, em contraposição a Bobbio, na articulação deste bloco a estrutura socioeconômica é um componente decisivo.

$\mathrm{Na}$ análise destas afirmações, creio, leva a reforçar a concepção de bloco histórico, enquanto as forças materiais são o conteúdo e as ideologias a forma, sendo esta distinção de conteúdo e de forma puramente dialética, posto que as forças materiais não seriam concebíveis historicamente sem forma e as ideologias seriam caprichos individuais sem a força material. (Gramsci, 1971, p. 57) 


\section{Carlos Nelson Coutinho coloca a visão mais enfática:}

[É incorreto acreditar] que a alteração efetuada por Gramsci o leve a retirar da infraestrutura essa centralidade ontológica-genética, explicativa, para atribuí-la a um elemento da superestrutura, precisamente a sociedade civil. Gramsci não inverte nem nega as descobertas essenciais de Marx, mas "apenas" as enriquece, amplia e concretiza, num quadro de aceitação plena do materialismo histórico. (Coutinho, 1980, p. 88 , apud Costa, 2002, p. 56)

Com a devida cautela, Portelli (1972, p. 62) faz uma breve síntese relevante. Afirma que para o pensador sardo não se pode cair no engano de sobrevalorizar um dos campos, pois, no plano político, se confundir ou ignorar a natureza orgânica das relações, corre-se o risco de se configurar o economicismo, que desemboca em duas atitudes aparentemente opostas: o sindicalismo e o aventureirismo.

No primeiro caso, a sociedade civil é assimilada à estrutura, o que conduz a limitar-se a uma política econômico-corporativa de tipo tradeuninista e, politicamente, à passividade na espera de que a evolução "natural" da estrutura tenha por consequência a alteração da superestrutura-reflexo. No segundo caso, a fim de dissimular a ausência de toda análise orgânica do bloco histórico, a superestrutura torna-se o campo do "irracional", do arbitrário (no sentido bergsoniano de élan vital), e também da "espontaneidade". Este economicismo aventureirista se expressa, no plano político, pelo sindicalismo revolucionário e no espontaneísmo. (Gramsci, 1962, p. 92)

No que se refere à "segunda possibilidade de erro, o ideologismo, este tem os mesmos efeitos (análise que ele faz de Benedetto Croce); se é excluída a política, a história se limita a uma história das ideias. [...] O ideologismo, mesmo ao revés do economicismo, pode igualmente conduzir à uma exaltação do 'elemento voluntarista e individual', na medida em que nega as realidades da estrutura".

\section{Participação cultural}

Um tópico também motivo de debates e interpretações divergentes se funde na cultura. Para Gramsci, a hegemonia é gnosiológica, relaciona poder e saber. Nessa problemática, ele diz que o senso comum é um instrumento de dominação 
de classe. Numa ótica ampla, o senso comum, a consciência cotidiana, contém em si uma concepção de mundo ingênua, desarticulada, desagregada, dogmática e conservadora. Geralmente, ela favorece a passividade e a aceitação da ordem social, sendo, portanto, um obstáculo para uma nova hegemonia revolucionária. A classe dominante faz com que sua ideologia se popularize, seja incorporada mecanicamente pelo povo, pela falta de uma educação crítica. Nas palavras de Gramsci, não significa que "não existam verdades no senso comum [...], significa que o senso comum é uma concepção equívoca, contraditória e multiforme, e que fazer referência ao senso comum como prova de veracidade é um contrassenso" (Gramsci, 1966, p. 125). Positivamente, ele acrescenta a ideia de que nessa concepção das massas há um núcleo fecundo — "bom-senso" —, cujo significado se refere à existência no senso comum de elementos de racionalidade e humanização, de traços de um pensamento crítico e contra-hegemônico. É nele que os intelectuais orgânicos revolucionários devem se apoiar. "A filosofia da práxis não tende a manter os 'simples' em sua primitiva filosofia de senso comum, mas, ao contrário, busca conduzi-los para uma concepção superior da vida [...] a fim de construir um bloco intelectual-moral que torne possível um progresso intelectual de massa" (Gramsci, 1966, p. 19). Neste pano de fundo, na realidade brasileira foi concebido o senso comum como cultura popular, que resgata com convergência relevante o bom-senso gramsciano.

Isto requer uma reforma intelectual e moral, uma reforma cultural, novos conteúdos educativos e nova relação pedagógica entre educador e educando que elimine a posição tradicional de conceber o outro como objeto. Por isso, a nova hegemonia é um processo político e gnosiológico. "Toda relação de hegemonia é um ato pedagógico"; essa relação pedagógica "não pode ser reduzida a relações especificamente escolares" (Gramsci, 1966, p. 34). Para ele não se trata de uma educação "analítica", isto é, de uma "instrução", de um acúmulo de noções, e sim de uma educação "sintética", da difusão de uma concepção de mundo convertida em norma de vida" (Gramsci, 1966, p. 222). Como aponta Acanda, "não se trata de difundir um conhecimento instrumental entre as massas, mas de universalizar a capacidade de pensamento crítico" (Acanda, 2006, p. 210). Como foi difundido e reconhecido, esse pensamento crítico exigiu uma nova concepção educativa, concretizada no "método Paulo Freire", que acentua a "pedagogia do oprimido" com outra visão e situa o futuro no "inédito viável". Da mesma maneira, como indicado anteriormente, a metodologia do MEB também redefinia a cultura popular e o lugar dos trabalhadores. 
Podendo-se também exemplificar com os Centros Populares de Cultura e os Movimentos de Cultura popular da década de 1960. E, nos tempos de hoje, com a educação ministrada num subconjunto expressivo de entidades de educação popular vigentes no Brasil e nos acampamentos do MST, cujos objetivos e métodos buscam estratégias transformadoras do capitalismo e controle social das políticas governamentais que valorizam o privado, o mercado, a globalização neoliberal hegemônica.

\section{Democracia}

Como é sabido, setores das esquerdas (e mesmo setores de direita ou de centro) têm feito análises de monta sobre os avanços dos regimes de democracia liberal-representativa, sobretudo como resultante das lutas contra as ditaduras e regimes autoritários. Em sentido contrário, facções das esquerdas, desde os fundadores do marxismo e seguidores nas diversas épocas, a combatem com vigor, principalmente pelos meios que utiliza para condenar, subsumir, incorporar, manipular os interesses estruturais e mesmo conjunturais das classes trabalhadoras, impondo, por meio do Estado e da classe hegemônica, o capitalismo clássico e o presente determinado pela globalização neoliberal. Já no passado mais remoto e, basicamente depois da ruptura do socialismo real, intelectuais, dirigentes partidários e sindicais, que ainda concebem como viável a construção de um novo socialismo (socialismo democrático, ecossocialismo etc.), defendem uma democracia que seja participativa, pública, capaz de romper com as imensas desigualdades sociais e as incertezas sobre reformas em curso e pretendidas pelos setores dominantes.

Uma afirmação categórica nessa direção pode ser apreciada nas palavras de Carlos Nelson Coutinho (1984, p. 25):

[...] para os que lutam pelo socialismo em nome dos interesses histórico-universais dos trabalhadores, na convicção de que somente o socialismo é capaz de promover a libertação de toda a humanidade, a democracia política não é um simples princípio tático: é um valor estratégico permanente, na medida em que é condição tanto para a conquista quanto para a consolidação e aprofundamento dessa nova sociedade.

Em livro que escrevi, estudando as metamorfoses e veredas da educação popular (Wanderley, 2010), aponto como ela pode ser concebida nas dimensões 
educativas do aprender a conhecer, aprender a fazer, aprender a viver junto, aprender a ser, revisitando e ressignificando os processos de conscientização e politização formulados por Paulo Freire e pelo Movimento de Educação de Base, na década de 1960. Para que essa educação popular se efetive e adquira contornos transformadores profundos, na construção de uma sociedade mais humana, justa, livre, igualitária e solidária, situo a necessidade imperativa de teorizar e praticar alguns marcos norteadores: a construção da democracia (político-institucional, econômica, social, cultural e como modo de vida); o entendimento do que seja o público (com os atributos de universal, transparência, controle social, democratização, sustentabilidade, cultura cívica); e a permanência recorrente da utopia (entendida como "inédito viável" na concepção freiriana, e como "antecipação" na elaboração de Jerzy Szachi).

Recebido em 4/10/2011 - Aprovado em 28/11/2011

\section{Referências bibliográficas}

ACANDA, Jorge Luis. Sociedade civil e hegemonia. Rio de Janeiro: Ed. UFRJ, 2006.

AGGIO, Alberto (Org.). Gramsci: a vitalidade de um pensamento. São Paulo: Unesp, 1998. ANDERSON, Perry. Las antinomias de Antonio Gramsci. Cuadernos Políticos, México: Era, n. 13, jul./set. 1977. . As antinomias de Gramsci. São Paulo: Joruês, 1986.

AVRITZER, L. (Org.). Sociedade civil e democratização. Belo Horizonte: Del Rey, 1994. BOBBIO, Norberto. Ensaios sobre Gramsci e o conceito de sociedade civil. 2. ed. São Paulo: Paz e Terra, 2002.

BORDIN, L. O marxismo e a teologia da libertação. Rio de Janeiro: Dois Pontos, 1987.

BOSI, Alfredo. O trabalho dos intelectuais segundo Gramsci. Debate e Crítica. São Paulo, n. 6,1975 .

BUCI-GLUCKSMANN, Christine. Gramsci y el Estado (hacia una teoria meterialista de la filosofia). 4. ed. México: Siglo XXI, 1979.

CHAUI, Marilena. Conformismo e resistência: aspectos da cultura popular no Brasil. São Paulo: Brasiliense, 1986. 
COHEN, J.; ARATO, A. Sociedad civil y teoria política. México: Fondo de Cultura Económica, 2000.

COHN, Amélia. Estado, sociedade civil e institucionalização da participação no Brasil: avanços e dilemas. In: IPEA. Estado, instituições e democracia: democracia. Brasília: Ipea, 2010. Livro 9, v. 2.

COSTA, Sergio. Esfera pública, sociedade civil e movimentos sociais na América Latina. Novos Estudos Cebrap, São Paulo, n. 38, mar. 1994.

. Sociedade Civil e espaço público. In: . As cores de Ercília. Belo Horizonte: UFMG, 2002.

COUTINHO, Carlos Nelson. Os conselhos de fábrica e o jovem Gramsci. In: . A democracia como valor universal. 2. ed. Rio de Janeiro: Salamandra, 1984.

Gramsci: um estudo sobre seu pensamento político. 3. ed. Rio de Janeiro: Civilização Brasileira, 2007.

DAGNINO, Evelina (Org.). Sociedade civil e espaços públicos no Brasil. Rio de Janeiro: Paz e Terra, 2002.

; OLVERA, A. J.; PANFICHI, A. (Orgs.). A disputa pela construção democrática na América Latina. Rio de Janeiro: Paz e Terra; Campinas: Unicamp, 2006.

DURIGHETTO, M. L. Sociedade civil e democracia: um debate necessário. São Paulo: Cortez, 2007.

GRAMSCI, A. Ordinenuovo. Turim: Einaudi Ed., 1954.

. Notas sobre Maquiavelo, sobre política y sobre el Estado moderno. Buenos Aires: Lautaro, 1962.

. Passato e presente. Torino: Einaudi Ed., 1964.

. El materialimo histórico y la filosofia de Benedetto Croce. Buenos Aires: Nueva Visión, 1971. 1972.

. Los intelectuales y laorganización de La cultura. Buenos Aires: Nueva Visión, . Cadernos do cárcere. Rio de Janeiro: Civilização Brasileira, 1999-2002.

GRUPPI, Luciano. O conceito de hegemonia em Gramsci. Rio de Janeiro: Graal, 1978.

HOBSBAWM, Eric. As décadas de crise. In: . Era dos extremos: o breve século XX 1914-1991. São Paulo: Companhia das Letras, 1995a.

. A crise atual das ideologias. In: SADER, Emir (Org.). O mundo depois da queda. Rio de Janeiro: Paz e Terra, 1995b. 
IPEA. Estado, instituições e democracia: democracia. Brasília: Ipea, 2010. Livro 9, v. 2. KONDER, Leandro. O futuro da filosofia da práxis. Rio de Janeiro: Paz e Terra, 1992.

LAVALLE, A. G. Sem pena nem glória: o debate sobre a sociedade civil nos anos 1990. Novos Estudos Cebrap, São Paulo, v. 66, n. 6, p. 91-110, 2003.

LÜCHMANN, L. H. H. Participação, oportunidades e interesses. Civitas, revista de Ciências Sociais. Porto Alegre, v. 6, n. 1, 2006.

MUSCATELLO, B. (Org.). Gramsci e il marxismo contemporâneo. Roma: Riuniti, 1990.

NASCIMENTO, E. P. Hegemonia em Gramsci: uma teoria das relações políticas e nas relações modernas. Ensaios. São Paulo, n. 13, 1984.

NOGUEIRA, Marco Aurélio (Org.). Gramsci e a América Latina. Rio de Janeiro: Paz e Terra, 1988.

. Um Estado para a sociedade civil: tema éticos e políticos da gestão democrática.

São Paulo: Cortez, 2004.

NETTO, José Paulo. Democracia e transição socialista: escritos de teoria e política. Belo Horizonte: Oficina de Livros, 1990.

PORTANTIERO, J. C. Los usos de Gramsci. México: Plaza y Valdés, 1987.

PORTELLI, Hugues. Gramsci y el bloque histórico. 2. ed. Buenos Aires: Siglo XXI, 1974. Gramsci e a questão religiosa. São Paulo: Paulinas, 1984.

RAICHELIS, Raquel, WANDERLEY, L. E. Publicização, conselhos e reforma do Estado. In: MELO RICO, E. de; RAICHELIS, R. (Orgs.). Gestão social: uma questão em debate. São Paulo: Educ/IEE, 1998. (Texto apresentado no Seminário Internacional Reestruturação e reforma do Estado; o Brasil e a América Latina no Processo de globalização. São Paulo: FIA/FEA/USP, 18 a 21 de maio.)

RESTREPO, Luís Alberto. A relação entre a sociedade civil e o Estado: elementos para uma fundamentação teórica do papel dos movimentos sociais na América Latina. Tempo Social. São Paulo, v. 2, n. 2, p. 61-100, 1990.

SEMERARO, G. Gramsci e a sociedade civil: cultura e educação para a democracia. 2. ed. Petrópolis: Vozes, 2001.

SIMIONATO, Ivete. Gramsci: sua teoria, incidências no Brasil, influência no serviço social. Florianópolis: Ed. da UFSC; São Paulo: Cortez, 1995.

Razões para continuar utilizando a categoria sociedade civil. In: CANTOIA LUIZ, D. E. (Org.). Sociedade civil e democracia: expressões contemporâneas. São Paulo: Veras Editora, 2010. 
TATAGIBA, Luciana. Os conselhos gestores e a democratização das políticas públicas no Brasil. In: DAGNINO, Evelina (Org.). Sociedade civil e espaços públicos no Brasil. Rio de Janeiro: Paz e Terra, 2002.

TAVARES JESUS, Antonio. Educação e hegemonia no pensamento de Gramsci. São Paulo: Cortez, 1999.

VACCA, Giuseppe. Gramsci nelnostro tempo: hegemonia e interdependenza. Quaderni. São Paulo, 1992.

WANDERLEY, Luiz Eduardo. Educar para transformar: educação popular, Igreja Católica e Política no Movimento de Educação de Base. Petrópolis: Vozes, 1984.

Massas e sociedade civil: notas para um estudo. São Paulo em Perspectiva. São Paulo, v. 8, n. 2, abr.-jun. 1994.

Desafios da sociedade civil brasileira em seu relacionamento dialético com o Estado e o mercado. In: MELO RICO, E. de; RAICHELIS, R. (Orgs.). Gestão social: uma questão em debate. São Paulo: Educ/IEE, 1999.

. Educação popular: metamorfoses e veredas. São Paulo: Cortez, 2010. 